\title{
The Effect of Pedaling Cadence on the Kinetics of Oxygen Uptake during Severe Intensity Exercise
}

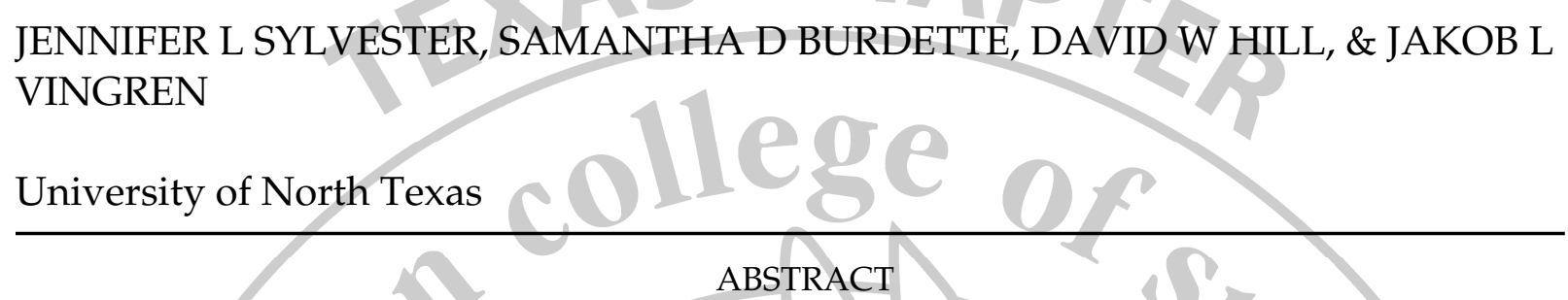

During exhaustive severe intensity exercise, the oxygen uptake (VO2) increases exponentially, with a time constant of $\sim 30 \mathrm{~s}$. After $\sim 1$ to 2 min, a slow component emerges and drives the VO2 to its maximum. Pedaling cadence contributes to the metabolic demand at a given work rate and affects several responses to cycling exercise. PURPOSE: To determine the effect of pedaling cadence on parameters of the twocomponent $\mathrm{VO} 2$ response profile during severe intensity exercise. METHODS: Eight women (mean \pm SD: age $22 \pm 1 \mathrm{yr}$, height $161 \pm 6 \mathrm{~cm}$, and weight $58.8 \pm 2.3 \mathrm{~kg}$ ) and $10 \mathrm{men}$ (age $23 \pm 1 \mathrm{yr}$, height $180 \pm 6 \mathrm{~cm}$, and weight $82.9 \pm 4.4 \mathrm{~kg}$ ) performed exhaustive constant-power cycle ergometer tests using pedaling cadences of $60 \mathrm{rpm}, 80 \mathrm{rpm}$, and $100 \mathrm{rpm}$. RESULTS: Times to exhaustion were smaller at higher cadences $(220 \pm 85<299 \pm 118<368 \pm 168 \mathrm{~s})$, whereas VO2max values were the same at all cadences (2786 $\pm 729=2768 \pm 749=2774 \pm 732 \mathrm{ml} / \mathrm{min}$ ). The mean response time of the primary response was faster at higher pedaling cadences $(27 \pm 5<32 \pm 5<37 \pm 5 \mathrm{~s})$; the amplitude of the primary response was greater at the highest cadence $(2045 \pm 577>1890 \pm 493=1899 \pm 515 \mathrm{ml} / \mathrm{min})$; and the time delay before the slow component was smaller at higher cadences $(85 \pm 11<105 \pm 17<118 \pm 19$ s). CONCLUSION: These results demonstrate that pedaling cadence affects the VO2 response profile. The higher cadences speed the primary or fundamental response and hasten the emergence of the slow component. This may have implications for the sport of cycling and should be considered when evaluating cardio-respiratory and metabolic responses to cycle ergometer exercise.

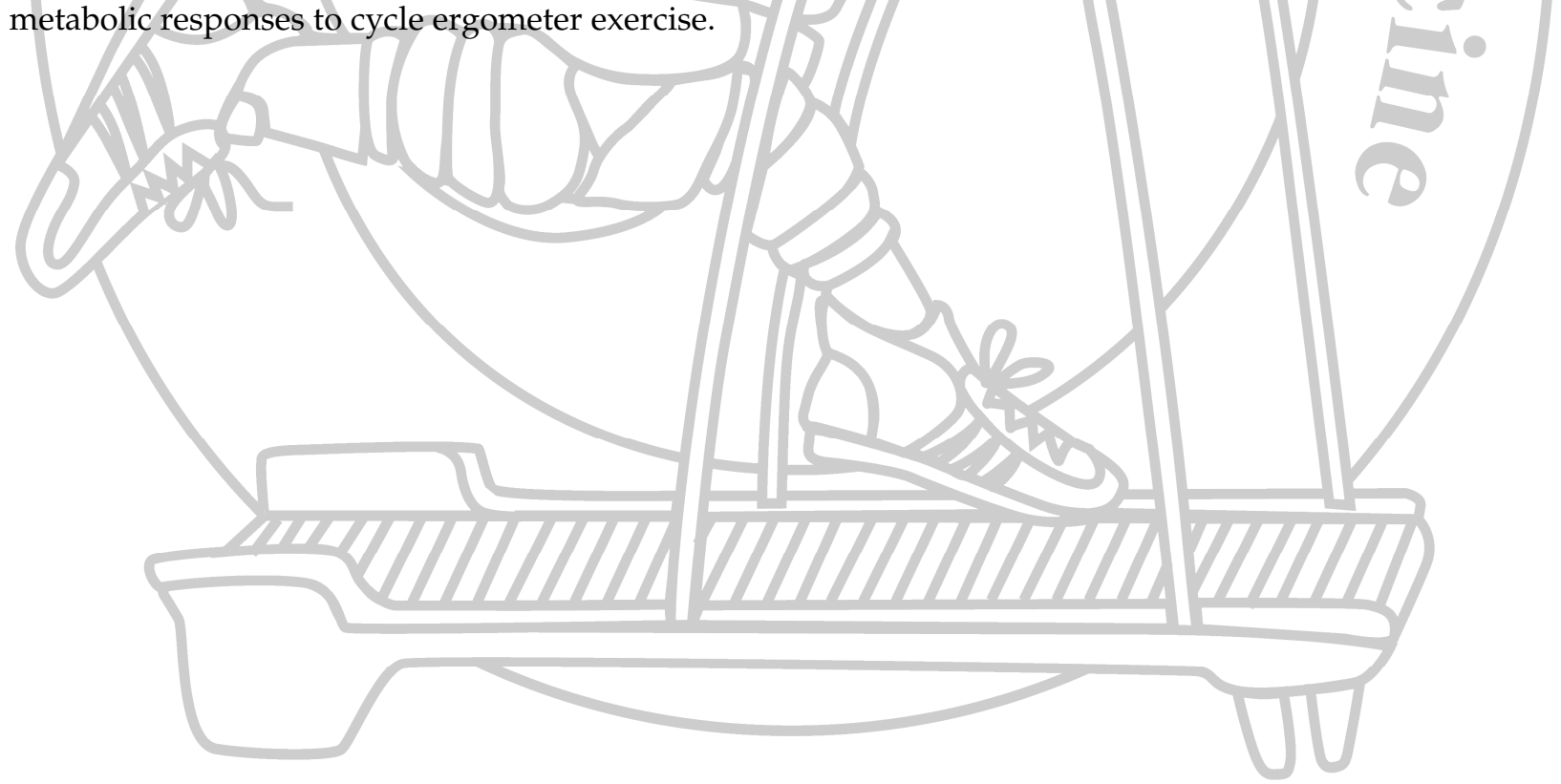

